Local government administration systems and local government accounting information needs: is there a mismatch?
International Review of Administrative Sciences 2019, Vol. 85(4) 708-725

(C) The Author(s) 2018

Article reuse guidelines: sagepub.com/journals-permissions DOI: I0.I I77/00208523 |7748732 journals.sagepub.com/home/ras

(S)AGE

\title{
Sandra Cohen
}

Athens University of Economics and Business, Greece

\section{Francesca Manes Rossi}

University of Salerno, Italy

\section{Eugenio Caperchione}

Modena and Reggio Emilia University, Italy

\section{Isabel Brusca}

University of Zaragoza, Spain

\begin{abstract}
After several years of reforms inspired by the New Public Management approach, public sector accounting and performance measurement systems continue to differ among countries. Based on previous literature and data collected through a questionnaire, we perform an exploratory study on the relations between local government administrative systems and local government accounting information needs in a sample of European countries characterized by a legalistic orientation. Our results reveal that there is a frequent mismatch between the needed accounting and performance measurement information for internal and external purposes assessed on the basis of the administrative system in place and the accounting information and performance
\end{abstract}

\section{Corresponding author:}

Sandra Cohen, Athens University of Economics and Business, Department of Business Administration, 76 Patission Street, Athens, Greece.

Email: scohen@aueb.gr 
measurement information required by the law for decision-making and accountability. Moreover, as the results reveal, legislation in European local governments only sporadically stipulates the information suitable to satisfy the information needs created by the different levels of financial and organizational autonomy of local government administration systems to be available.

\section{Points for practitioners}

In this article, we compare the accounting information and performance measurement information required by the law for decision-making and accountability to the information that we would expect to be available for internal and external purposes assessed on the basis of the administrative systems in local governments in I I (eleven) European countries. Apart from the mismatches identified, our results provide evidence that the accounting reforms towards accruals have been adopted without informing the systems related to administration, accountability, everyday decisions and assessment from oversight authorities. Unless this situation changes, the limited use of accruals should come as no surprise.

\section{Keywords}

accountability, accrual accounting, performance measurement, public administration typology

\section{Introduction}

Despite the introduction of accrual accounting systems in governments and public sector entities, cash or modified-cash information (Brusca et al., 2015; Reichard and Van Helden, 2016) still plays a pivotal role in political decisions at both the local and the national level (Heiling et al., 2013). Therefore, even though accrual accounting provides a tool that can offer a plethora of information useful for decision-making and control, not all local governments (LGs) exploit it as decision-making is sometimes based on other forms of information (e.g. cash information). Consequently, local administrators may not be interested in accrual accounting information as their performance assessment is done on the basis of other quantitative or qualitative measures (Van Helden et al., 2016). From this perspective, the lack of demand for accrual accounting data could be explained by the regulatory requirements of a country.

A large strand of public administration research has revealed that there are several well-established typologies of European LG administration systems (Heinelt et al., 2018; Hesse and Sharpe, 1991; Ladner et al., 2016; Loughlin, 2003). They are characterized by different considerations regarding, for example, 
central-LG relations, the allocation of functions and local autonomy, which, in turn, create different information needs for decision-making. In this article, we use the typology of Heinelt et al. (2018), which touches upon the financial and operational autonomy of LGs and can therefore be used to formulate hypotheses about the expected suitable accounting and performance measurement information required to meet informational needs for internal and external reporting.

The purpose of this study is to investigate the match or mismatch between, on the one hand, the information availability that would be expected based on the main characteristics of their administration systems (mainly proxied by financial autonomy and operational autonomy) and, on the other hand, the accounting and performance measurement information that is available in practice for decisionmaking and accountability purposes. In order to capture the availability of accounting and performance measurement information in practice, we do not just analyse the accounting and performance systems in place (e.g. accrual accounting systems), something that is related to the facade and might be ceremonially adopted by governments in order to ride the wave of New Public Management (NPM) reforms. Rather, we try to analyse whether the information generated by the accounting systems is formally required, also through legislation or regulations, for specific decision-making and accountability purposes that are relevant to the LG administration system. Therefore, we concentrate our analysis on countries having a legalistic orientation, based on the studies of Kuhlmann and Wollmann (2014) and Kuhlmann and Bouckaert (2016).

In most European countries, accrual accounting and performance measurement systems have been introduced by legal requirements, often initiated by national governments that have not clarified the specific objectives that this information would serve, as well as the expected consequences from the non-use of the information. Under these conditions, LGs may not have autonomy or decision capacity over the accounting systems applied and, in some cases, may have only limited jurisdiction over the performance measurement systems introduced. In this sense, LGs have introduced accounting and performance measurement reforms by trying to follow legal requirements; however, the literature shows that the cultural and organizational change needed to embed these reforms in routines and practices may not have taken place (Moynihan, 2005). Thus, inter-country differences occur regarding the type of reforms introduced, the way in which governments initiated performance measurement systems and the outcomes and results of these reforms. We aim at assessing if the information expected to be available for decisionmaking and control in different LG administrative systems coincides or diverges with the legal requirements for accounting and performance measurement information availability to meet the same purposes. In this realm, we build on the literature discussing LG administration systems in a selected sample of European countries, and we combine the results disclosed in previous studies with new input gathered through a questionnaire distributed among public sector accounting scholars. 
The article is structured as follows. The second section presents a review of the literature dealing with the adoption of accrual accounting and performance information in public entities, unveiling the gap between theoretical expectation and practice. The third section discusses classifications elaborated by scholars with regard to different typologies of $\mathrm{LG}$ administration systems. The fourth section clarifies the research design, while the fifth section highlights the data collected and discusses the possible link between LG systems and accounting and performance information requirements. The sixth section summarizes the main conclusions.

\section{The use of accounting and performance information in LGs: the divergence between theory and practice}

During the last two decades, LGs around the world have been immersed in deep structural reforms (Ongaro, 2009) inspired by the NPM principles. These reforms literally cover all areas of LGs, including governance and management. The introduction of accrual-based financial reporting and performance measurement has been a cornerstone in these reform processes (Hyndman and Connolly, 2011; Lapsley et al., 2009) to improve management and accountability. This is because the adoption of a complete accrual system: permits the recognition of the effects of the transactions on the financial condition and performance of the entities at the time they occur; reflects all assets and liabilities, as well as revenues and expenses, capturing the long-term consequences of current decisions; and permits the measurement of the cost of providing goods and services, supporting a better allocation and management of public resources (Manes Rossi et al., 2016). Moreover, the financial constraints stemming from the financial crisis have increased the institutionalized pressures for introducing both accrual reporting systems and performance measurement and evaluation systems (Cavanagh et al., 2016; OECD, 2016).

In accordance with the theoretical frameworks issued by standard-setting boards (GASB, 1987; IPSASB, 2014), governmental financial reporting should provide information to assist users in assessing accountability and making economic, social and political decisions. The mediating role of accounting has also been discussed by scholars, who reveal the suitability of accounting to linking up distinct actors, aspirations and arenas (Miller and Power, 2013).

Original studies aimed to collect empirical evidence of user needs and to discuss which information is most relevant to them (Boyett and Giroux, 1978; Hay, 1994). However, relatively few users of public sector financial reports have been identified, including more recent studies dealing with different contexts and countries (Cohen et al., 2013; Guarini, 2016). The introduction of accrual-based reporting has been accompanied by the desire of standards setters, governments and institutions to implement performance measurement in public administrations (Arnaboldi et al., 2015). This is also supported by academics who point to a 
long list of users and uses (Kuhlmann, 2010b). Nevertheless, the use of this information in practice is mostly limited and unclear (Grossi et al., 2016).

The limited use of accrual accounting and performance information in practice has been attributed to several factors, such as: the gap between requirements and implementation (Brusca and Montesinos, 2013); cultural factors and the resistance of governments to introduce and use the information (Pollitt and Bouckaert, 2011); the complexity of accrual accounting information (Hyndman, 2016) or the complexity of the organizations themselves (De Lancer and Steccolini, 2015); and resistance to changing their routines (Moynihan, 2005). Scholars also refer to the relevance of the context to the use and usefulness of financial and non-financial information (Kuhlmann, 2010a; Van Helden et al., 2016), which could also influence the degree of ambiguity surrounding the goals of information in practice.

Last but not least, policy conditionality (i.e. the practice of requiring specific domestic policy changes as a condition for financial support) may also play a role in the use of accrual information for accountability to fund providers as fiscal goals are not based on cash. Policy conditionality has been a frequently used tool in the context of Eurozone crisis management (Spanou, 2016).

\section{Typologies of LG administration systems}

There are several well-established typologies of European LG systems (see, e.g., Hesse and Sharpe, 1991; Loughlin, 2003). In this article, we use the typology developed by Heinelt et al. (2018), which touches upon parameters that can be used in order to build hypotheses regarding the accounting and performance measurement information that would better fit the characteristics of the different LG settings. Their index comprises two dimensions. The first refers to financial autonomy and is measured by two variables, namely, municipal spending as a percentage of gross domestic product (GDP) and local tax autonomy (i.e. the proportion of local revenues coming from locally controlled taxes). The second dimension corresponds to operational (functional) autonomy.

While the first dimension is more straightforward, the second touches upon several parameters, which relate to: the scope of municipal functions (institutional depth); the flexibility in municipalities to decide autonomously about their administrative structure for providing services (institutional autonomy); the control of upper levels of government over the municipalities (administrative supervision); the proportion of LG revenues derived from their own sources to total resources (financial self-reliance); and the proportion of unconditional financial transfers to total financial transfers received by the LG (transfers system). We have used a scoring system that categorizes LGs into nine groups based on their scores on these two dimensions. The scoring is not precise, but it gives a qualitative categorization. More specifically, each country's LGs are characterized as high, medium and low in terms of financial and operational autonomy.

In this study, apart from the typology of Heinelt et al. (2018), we also use the country classifications based on Kuhlmann and Wollmann (2014) and Kuhlmann 
and Bouckaert (2016). These country types are used in order to better understand whether there is a relation between different types of systems and different types of jurisdictions. Table 1 presents only the country classification types that correspond to our country sample (i.e. we do not include the Anglo-Saxon type as it does not have a legalistic orientation, which is a prerequisite in order to administer the questionnaire). Through the country type description in Table 1, we mainly concentrate on three dimensions, namely, legal tradition, level of decentralization and citizen participation in local administration. The five country types we refer to are: (1) the Continental European Napoleonic type (CEN); (2) the Continental European Federal type (CEF); (3) the Nordic type (NO); (4) the Central-Eastern European type (CEE); and (5) the South-Eastern European type (SEE).

\section{Research design}

In this study, we hypothesize that the different local administration systems create different situations in relation to the extent to which accounting and performance information is needed for decision-making and accountability, and this should be reflected in the legal requirements. LGs that operate in legalistic administrative environments have specific stipulations in relation to accounting information for decision-making and accountability embedded in the law. Otherwise, even if accounting information is available, it would not be binding for decision-making and accountability purposes. Therefore, we do not study practice in individual entities (which may eventually present differences in concrete adoption), but try to assess a match or a mismatch between what is requested in the law and the expected needs defined in accordance with the local administrative system in place. We acknowledge that practice at the individual LG level might be influenced by a plethora of factors that are beyond the scope of the present study.

Our normative expectations about the needs for accounting and performance information for internal use and external disclosure are based on the following considerations (see Table 1):

a. Financial autonomy is related to municipal spending to GDP and local tax autonomy. This means that financial autonomy is related to local decisionmaking power over expenditures and financing, and it has an income and expenditure perspective (Oulasvirta and Turala, 2009). Accounting and performance measurement can provide useful information to local managers in taking decisions about how services are produced and delivered, as well as for other internal purposes. Moreover, politicians can base their decisions about fiscal and financial policies (e.g. fees, taxes and indebtedness) on the basis of accounting information and performance indicators. Thus, the higher the financial autonomy of the LGs, the greater the need for better accounting and performance measurement information for internal use.

b. Functional autonomy is related to institutional autonomy, and it refers to the power of the governments to determine public actions and other 


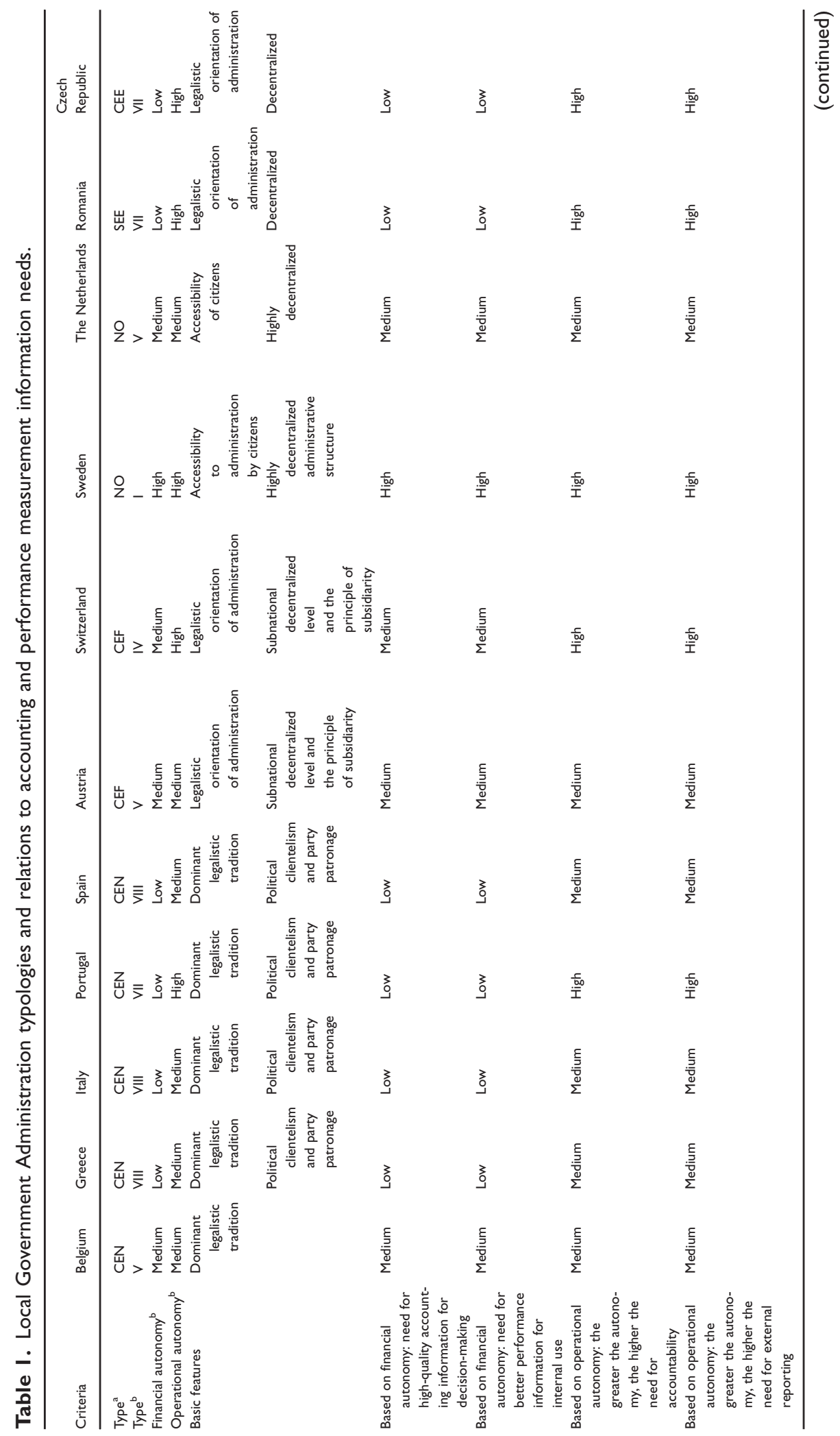




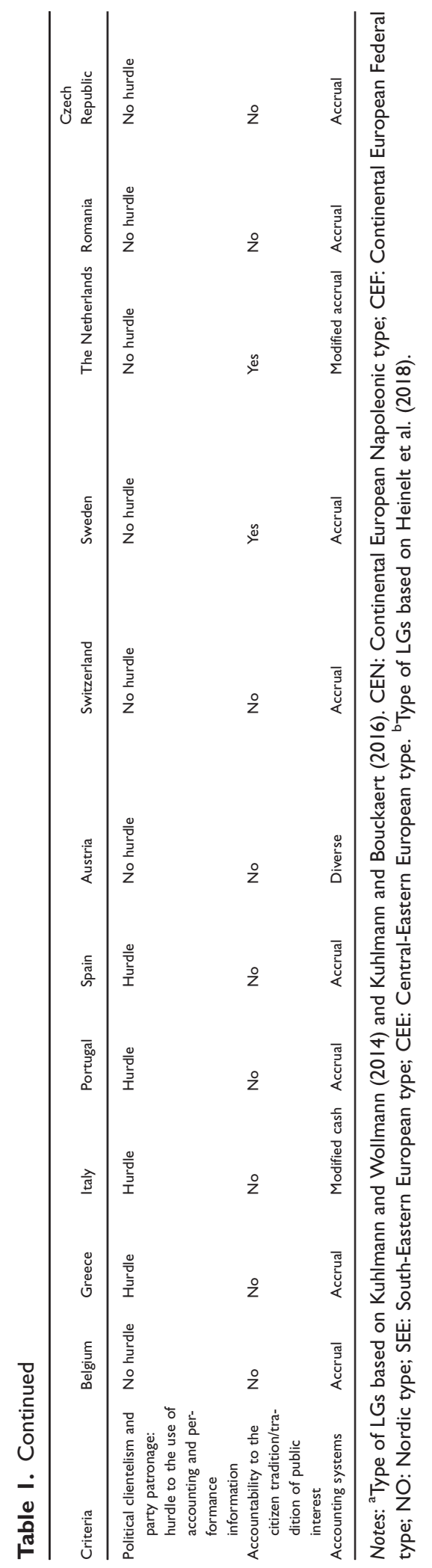


organizational aspects. Therefore, we expect that this level of autonomy influences the need for the availability of accounting information for accountability and external reporting. Thus, the higher the functional autonomy of the LGs, the greater the need for better accounting information for accountability and external reporting.

To assess whether our assumptions are valid, we performed an exploratory analysis. As in previous research (Hoque, 2008; Scott and Falcone, 1998), we aim at providing a broad picture of the legal requirements in relation to accounting and performance measurement information in selected countries. This approach would provide input to analyse whether what would be expected as suitable or adequate on the basis of the local administrative systems in place coincides with or diverges from the corresponding legal requirements. Moreover, it would reveal whether the laws formally ask for accrual accounting information to be used for decision-making and accountability purposes.

As our assumptions are closely related to the legalistic character of the LGs, we identified a list of countries having a legalistic orientation, based on Kuhlmann and Wollmann (2014) and Kuhlmann and Bouckaert (2016). These are countries that fall within the CEN, CEF, NO, CEE and SEE categorizations discussed earlier. As the study is exploratory, we selected some of these countries by trying to have at least one of them per type. What we would expect in relation to accounting and performance measurement information availability is summarized in Table 1 .

In order to get input about the different legal requirements in relation to the accounting and performance measurement information availability in different LG national settings, we developed a questionnaire. It aimed at taking stock of the extent to which the legal framework of LGs requires accrual accounting information, budgetary accounting information (i.e. mainly cash-based) and performance indicators (based on cash or accrual data) for internal and management purposes and for external and evaluation purposes. The questionnaire (see Appendix 1 available online) was developed in such a way as to allow us to set up four scores, which refer to: (1a) accounting information for decision-making; (1b) performance measurement information for decision-making; (2a) accounting information for accountability purposes; and (2b) performance measurement information for accountability purposes.

Each questionnaire was completed by a scholar familiar with the legal requirements at the LG level of the relevant country. Questionnaires were distributed and collected from March to April 2017 and, when necessary, some interviews with the responding scholars took place to clarify some aspects. Inviting scholars to complete the questionnaire was considered the best way to follow as legal documents are mainly written in national languages and are numerous and dispersed. We trust that the knowledge of an expert scholar would provide robust input to this process. Combining interviews, questionnaires and documents is typical for accounting case studies (Modell, 2005; Yin, 2013). 


\section{In search of the link between local administrative systems and accounting and performance information}

The data collected were used as the main source to score the sample countries, complemented however with existing literature and public documents. The scoring was made on the scale of low, medium and high in relation to what is stipulated in the law for both internal and external purposes. More specifically, in accordance with the dominant theory recognizing the higher informative power of accrual data, we assigned a score in accordance with the kind of information required by law, as follows: high in case accrual is mostly required; medium when accrual information is partially required; and low when only budgetary accounting information is required. When the law asks for very limited information, we assigned an extra low score. For each of the four types of information needs, labelled 1a, 1b, 2a and $2 \mathrm{~b}$ in the previous section, a score (high, medium, low or extra low) was given.

By comparing our normative expectations (see Table 1) with the actual situation as reflected in the scores, we assess whether the legal requirements coincide with or diverge from the hypothesized needs based on the administrative structures. Table 2 presents the values for these four scores in comparison to our normative expectations already presented in Table 1.

This comparison presents the cases where the needs stemming from the types of financial and operating autonomy match the existing stipulations in the law about the availability of accounting and performance information to be used for decision-making and accountability. These cases are marked with the word 'Match'. However, there are cases where the expected needs do not coincide with what is included in the law. We can distinguish between two possibilities: the legal requirements regarding the availability of accounting and performance information, both for internal and external purposes, are more extensive than the expected needs (this is indicated with ' + ' in Table 2); and the law asks for the available accounting and performance measurement information to be less sophisticated compared to what was expected on the basis of the specific profile of the LGs (this is indicated with '-' in Table 2). The number of ' + ' or ' - ' in the difference column tries to quantify the extent of divergence.

At the core of the discussion of results collected, we assume that the level of fiscal autonomy and operational autonomy creates different needs for accounting and performance measurement information availability, as presented in Table 1. Thus, for those LGs for which expectations are low or medium, it would be foreseen that they could satisfy their decision-making and reporting needs with less sophisticated accounting tools, such as those that relate to non-accrual accounting. This would provide a reasonable explanation of the fact that while LGs have been compelled by regulations to adopt more sophisticated accounting tools, they do not seem to base their decisions on the information generated from them. Nevertheless, they would be obliged to do so if the law was explicit on decisions and accountability reporting based on this type of information. In any case, as the 


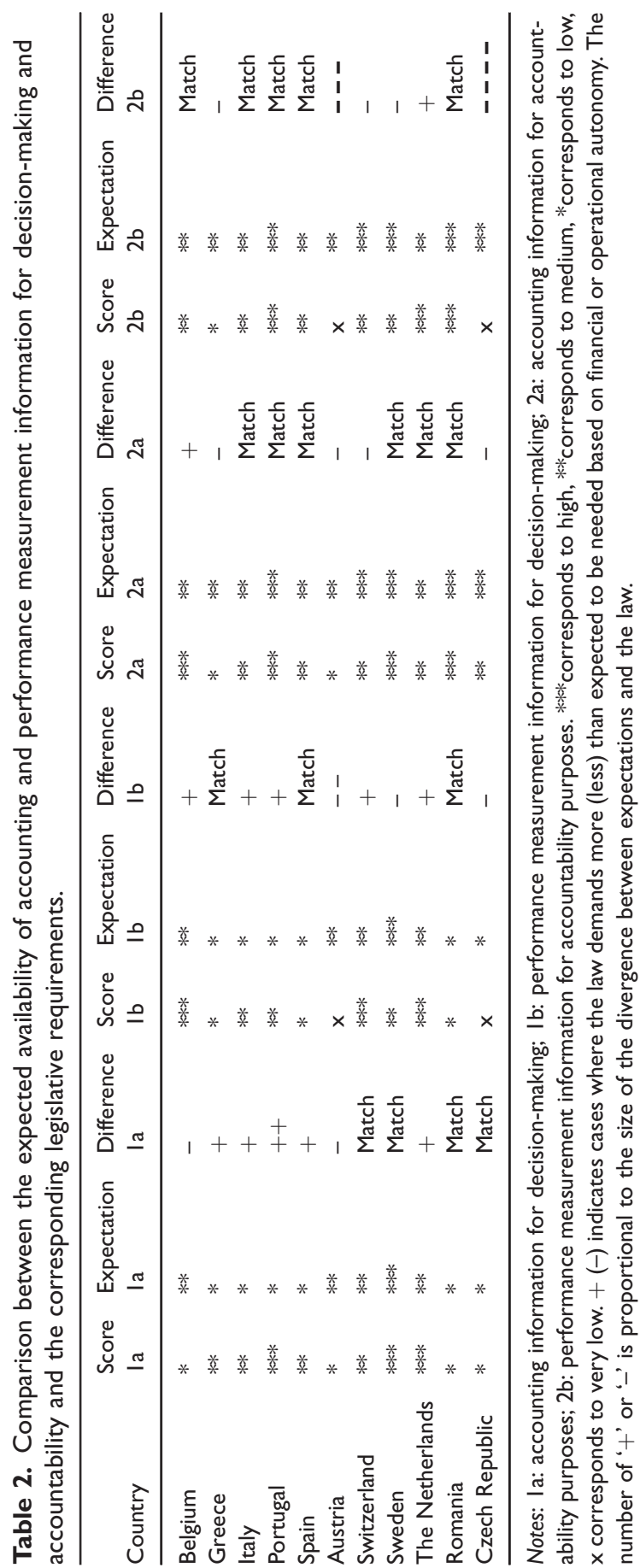


accrual accounting systems are in place in several LGs, the information would be easily available.

Surprisingly, an important finding from the analysis of the scores is that in not all countries are there legal requirements for the extensive availability of accounting and performance information for internal and external use. This is evident from the fact that no country from the sample has been classified as having high requirements for all four scores. This can be, at least to a certain extent, part of the explanation for the non-use of accrual accounting information. Of course, other factors play a role, such as the expertise of the users, their perceptions about the suitability of a certain type of information to solve problems, NPM influences or public sector traditions, to name just a few. However, especially for countries with legalistic traditions, the influence of the legal requirements cannot be neglected. Therefore, when the legal framework requires the implementation of accrual accounting, it should define when, how and for what this information is going to be used. Otherwise, it seems that there is some decoupling between the reform introduced and its actual institutionalization.

CEN-type countries seem to be split into two subgroups. The first subgroup includes Belgium and Portugal, where the law asks for medium to high information for decision-making and accountability (except for 1a for Belgium), and the second subgroup includes Greece, Italy and Spain, where the law asks for low to medium information for the same purpose. Thus, there are countries that have adopted accrual accounting, such as Spain and Greece, and both the expectations and the scores make it clear that this type of information is not sufficiently embedded in decision-making and accountability disclosure. These countries are less likely to adequately exploit accrual accounting information, notwithstanding its availability. Therefore, unless there is a change in the legal requirements, a significant take-up of this information cannot be expected. In this case, a decoupling is evident.

In the group of CEF-type countries, Austria and Switzerland are included. In Austria, the four scores correspond to low or extra low, which shows that the law does not really require high-quality accounting information to be used in several cases of decision-making and accountability. However, clear conclusions cannot be derived for Austria as there is not a single accounting system adopted by all LGs in the country. Nevertheless, based on the local administration structure, the expectations were of medium needs in all the cases. As a result, important differences appear. In Switzerland, the expectations were high to medium and results also show a mismatch in three out of the four cases, albeit of a small magnitude. Nevertheless, the medium scores in Switzerland should be interpreted by taking into account that Swiss LGs adopt accrual budgeting.

Our $N O$ sample countries (the Netherlands and Sweden) have embedded in their laws medium to high requirements in terms of accounting and performance information, both for internal and external use. The small divergence between the expectations and the law might be explained or bridged through the fact that, in these countries, there is accessibility to the administration by citizens. For example, 
in Sweden, the principle of free access to information makes it possible to obtain all necessary information from LGs (Nyman et al., 2005).

Romania (SEE country) is the only country in the sample where all the scores match with the expected needs. What is interesting is the divergence regarding the needs of accounting information and performance measurement information for internal and external use. While, in the first case, needs and legal requirements do match at the low category, in the second case, they match at the high category. Finally, in the Czech Republic (CEE country), the requirements are lower to what was expected based on the public administration structure. However, this might change thanks to the undergoing process of administrative reforms in LGs.

The difference columns in Table 2 also show that except for the cases where the law regulates the same qualitative level of information for internal and external use to that of the hypotheses (the matching case), the cases where a ' + ' exists in the column of differences for $1 \mathrm{a}$ and $1 \mathrm{~b}$ are much more than those in columns $2 \mathrm{a}$ and 2b. A clear trend for more requirements than what was expected for the availability of information for decision-making compared to the availability of information for accountability emerges.

\section{Conclusions}

The need for harmonized accounting information based on accrual data throughout European countries has been prompted both by scholars and by institutions during recent years, especially in Europe (Christiaens et al., 2010; EU Commission, 2013). Notwithstanding the claimed influential role of the national context, and the intensive research in the public administration domain to categorize countries in accordance with their administrative systems in place (Heinelt et al., 2018; Kuhlmann, 2010a), no studies - to the best of our knowledge - have so far investigated the relationship between the needs that these administrative systems create in relation to accounting information and performance measurement information for decision-making and accountability. Moreover, this study takes stock of the legal requirements in relation to the availability of accounting and performance measurement information for internal and external use. We explicitly focus on legal requirements as the study deals with countries where public administration is highly reliant on legislation.

Elaborating on different sources, including a questionnaire distributed among selected scholars, a frequent mismatch between the needed accounting and performance measurement information for internal and external purposes assessed on the basis of the administrative system in place and the accounting information and performance measurement information required by the law for decision-making and accountability emerges. However, what is of utmost importance is that laws do not ask in all cases for accrual accounting information and accrual performance measurement information to be available in order to be used for decision-making and accountability purposes, even if accruals are there. It seems that the accounting reforms towards accruals have been adopted without informing the systems 
related to administration, accountability, everyday decisions and assessment from oversight authorities. Unless this situation changes, the limited use of accruals should come as no surprise. Nevertheless, the use of accruals might be intensified in the future for another reason. Several European countries operate under policy conditionality (Spanou, 2016), so accruals are needed to assess whether general government fiscal rules are met. However, this is related not to accrual accounting financial statements, but to pieces of information measured under accruals (e.g. liabilities).

All in all, accounting information is not a 'one size fits all' attribute. As results collected demonstrate, the demand for accounting data and performance indicators may differ among countries, and a mismatch between what the administrative system in place is supposed to require and what the law stipulates to be available may occur.

This article contributes to public sector accounting research in a threefold manner. First, by connecting administrative systems and accounting requirements introduced by the law, we fill a gap not yet investigated by scholars. Our results can contribute to the discussion about accounting harmonization in Europe, providing evidence for the reasons why the introduction of harmonized accounting standards along with national accounting systems could go hand in hand in a way coherent with the local administrative systems in place (Manes Rossi et al., 2016). Decisionmaking and accountability at the LG level could be based on existing accounting systems that correspond, more or less, to the information needs related to the local administrative systems.

Second, our exploratory study, based on previous research, documents and questionnaires complemented with interviews, provides some first interesting insights that may be of inspiration to policymakers. In fact, the demand for legislation aligned to the information needs embedded in a specific country's administrative system emerges clearly. As results reveal, only sporadically is legislation in European LGs aligned with information suitable to satisfy information needs connected with the levels of financial and organizational autonomy resulting from the administrative system in place.

A further contribution, which also draws a future research avenue, is the emerging need to empirically verify whether the progressive adoption of accrual accounting systems is sufficient to satisfy the needs for specific information that would support managers and politicians in their decisions, or whether management accounting information based on accrual data should be required by the law in order to support these information needs.

This research presents some limitations. The first limitation is related to the methodology used. The analysis is based on questionnaires completed by scholars and not LG administrators. In some cases, there is only one questionnaire per country category. Moreover, the analysis is based on legal requirements, while, in practice, a divergence between the law and its enforcement may occur, and other means apart from the law may introduce binding requirements. The second limitation is related to the type of study. As it is an exploratory study, it provides 
limited insights into how managers and politicians perceive the relevance and usefulness of accounting and performance information, and to what extent they make use of it. Thus, empirical analysis digging deeper into the mediating role of accounting information in linking different actors and arenas would support the 'long and winding road' towards public sector accounting harmonization. This is a challenge to be considered by European stakeholders in the public domain, connecting regulators, standards setters, the accounting profession, scholars, politicians and managers in a wide project aimed at unravelling what is really needed for a better public administration.

\section{Funding}

The author(s) received no financial support for the research, authorship and/or publication of this article.

\section{Supplementary material}

Supplementary material is availabe for this article. Please see http;//journals.sagepub.com/ home/ras

\section{References}

Arnaboldi M, Lapsley I and Steccolini I (2015) Performance management in the public sector: The ultimate challenge. Financial Accountability and Management 31(1): 1-22.

Boyett AS and Giroux GA (1978) The relevance of municipal reporting to municipal security decisions. Governmental Finance, May, pp. 29-34.

Brusca I and Montesinos V (2013) From rhetoric to practice: The case of Spanish local government reforms. Financial Accountability and Management 29(4): 354-377.

Brusca I, Caperchione E, Cohen S et al. (eds) (2015) Public Sector Accounting and Auditing in Europe. The Challenge of Harmonization. Basingstoke: Palgrave Macmillan.

Cavanagh J, Flynn S and Moretti D (2016) Implementing Accrual Accounting in the Public Sector. Washington: International Monetary Fund.

Christiaens J, Reyniers B and Rollé C (2010) Impact of IPSAS on reforming governmental financial information systems: A comparative study. International Review of Administrative Sciences 76(3): 537-554.

Cohen S, Kaimenakis N and Venieris G (2013) Reaping the benefits of two worlds: An explanatory study of the cash and the accrual accounting information roles in local governments. Journal of Applied Accounting Research 14(2): 165-179.

De Lancer P and Steccolini I (2015) Introduction to symposium: Performance and accountability in complex settings - Metrics methods, and politics. International Review of Public Administration 20: 41-46.

EU (European Union) Commission (2013) COM 2013114 final. Report from the Commission to the Council and the European Parliament. Towards implementing harmonised public sector accounting standards in Member States. The suitability of IPSAS for the Member States, Brussels. Available at: http://eur-lex.europa.eu/legal-con tent/EN/TXT/PDF/?uri=CELEX:52013DC0114\&from $=$ en

GASB (Governmental Accounting Standards Board) (1987) Concepts Statement No. 1 Objectives of Financial Reporting. Norwalk: GASB. 
Grossi G, Reichard C and Ruggiero P (2016) Appropriateness and use of performance information in the budgeting process: Some experiences from German and Italian municipalities. Public Performance and Management Review 39(3): 581-606.

Guarini E (2016) The day after: newly-elected politicians and the use of accounting information. Public Money and Management 36(7): 499-506.

Hay DC (1994) Who uses public sector external reports: An exploration. Accounting Forum 17(4): 47-65.

Heiling J, Schührer S and Chan JL (2013) New development: Towards a grand convergence? International proposals for aligning government budgets, accounts and finance statistics. Public Money and Management 33(4): 297-303.

Heinelt H, Hlepas N, Kuhlmann S et al. (2018) Local government systems: Capturing the institutional setting in which mayors have to act by typologies and indices. In: H Heinelt, A Magnier, M Cabria et al. (eds) Political Leaders and Changing Local Democracy - The European Mayor. Basingstoke: Palgrave Macmillan.

Hesse JJ and Sharpe LJ (1991) Local Government and Urban Affairs in International Perspective. Baden-Baden: Nomos.

Hoque Z (2008) Measuring and reporting public sector outputs/outcomes: Exploratory evidence from Australia. International Journal of Public Sector Management 21(5): 468-493.

Hyndman N (2016) Accrual accounting, politicians and the UK - With the benefit of hindsight. Public Money and Management 36(7): 477-479.

Hyndman N and Connolly C (2011) Accruals accounting in the public sector: A road not always taken. Management Accounting Research 22(1): 36-45.

IPSASB (International Public Sector Accounting Standards Board) (2014) Conceptual Framework for General Purpose Financial Reporting by Public Sector Entities. New York: IPSASB.

Kuhlmann S (2010a) New public management for the 'classical continental European administration': Modernization at the local level in Germany, France and Italy. Public Administration 88(4): 1116-1130.

Kuhlmann S (2010b) Performance measurement in European local governments: A comparative analysis of reform experiences in Great Britain, France, Sweden and Germany. International Review of Administrative Sciences 76(2): 331-345.

Kuhlmann S and Bouckaert G (eds) (2016) Local Public Sector Reforms: National Trajectories and International Comparisons. Governance and Public Management Series. Houndmills: Palgrave Macmillan.

Kuhlmann S and Wollmann H (2014) Introduction to Comparative Public Administration: Administrative Systems and Reforms in Europe. Cheltenham: Edward Elgar.

Ladner A, Keuffer N and Baldersheim H (2016) Measuring local autonomy in 39 countries 1990-2014, Regional and Federal Studies 263: 321-357.

Lapsley I, Mussari R and Paulsson G (2009) On the adoption of accrual accounting in the public sector: A self-evident and problematic reform. European Accounting Review 18(4): 719-723.

Loughlin J (ed.) (2003) Subnational Democracy in the European Union. Oxford: Oxford University Press.

Manes Rossi F, Cohen S, Caperchione E et al. (2016) Harmonizing public sector accounting in Europe: Thinking out of the box. Public Money and Management 36(3): 189-196. 
Miller P and Power M (2013) Accounting, organizing, and economizing: Connecting accounting research and organization theory. Academy of Management Annals 71: 557-605.

Modell S (2005) Triangulation between case study and survey methods in management accounting research: An assessment of validity implications. Management Accounting Research 162: 231-254.

Moynihan DP (2005) Goal-based learning and the future of performance management. Public Administration Review 65: 203-216.

Nyman C, Nilsson F and Rapp B (2005) Accountability in local government: A principalagent perspective. Journal of Human Resource Costing \& Accounting 9(2): 123-137.

OECD (Organisation for Economic Co-operation and Development) (2016) Accrual Practices and Reform Experiences in OECD Countries. Paris: OECD Publishing.

Ongaro E (2009) Public Management Reform and Modernization. Trajectories of Administrative Change in Italy, France, Greece, Portugal and Spain. Cheltenham: Edward Elgar.

Oulasvirta L and Turala M (2009) Financial autonomy and consistency of central government policy towards local governments. International Review of Administrative Sciences 75(2): 311-332.

Pollitt C and Bouckaert G (2011) Public Management Reform. A Comparative Analysis. New York, NY: Oxford University Press.

Reichard C and Van Helden J (2016) Why cash-based budgeting still prevails in an era of accrual-based reporting in the public sector. Accounting, Finance and Governance Review 23(1/2): 43-65.

Scott PG and Falcone S (1998) Comparing public and private organizations: An exploratory analysis of three frameworks. The American Review of Public Administration 28(2): $126-145$.

Spanou C (2016) Policy conditionality, structural adjustment and the domestic policy system. Conceptual framework and research agenda. EUI Working Paper RSCAS 2016/60, Robert Schuman Centre for Advanced Studies.

Van Helden J, Argento D, Caperchione E et al. (2016) Editorial: Politicians and accounting information - a marriage of convenience? Public Money and Management 36(7): 473-476.

Yin RK (2013) Case Study Research: Design and Methods. Thousand Oaks: Sage Publications.

Sandra Cohen is Associate Professor of Accounting at Athens University of Economics and Business, Greece. Her research interests lie in the fields of public sector accounting, management accounting and intellectual capital. Her research has been published in several ranked journals.

Francesca Manes Rossi is Associate Professor of Accounting at the University of Salerno, Italy. She researches and consults in performance measurement, intellectual capital, sustainability and integrated reporting, auditing and accounting standards in both the private and public sectors (International Accounting Standards/International Financial Reporting Standards - IAS/IFRS and International Public Sector Accounting Standards - IPSASs). 
Eugenio Caperchione is Professor of Public Management and Public Sector Accounting at Modena and Reggio Emilia University, Italy. His main research area is public sector accounting, on which he has published extensively. As he believes comparisons among countries are central in research, he works in close connection with his colleagues in the Comparative International Governmental Accounting Research (CIGAR) network. He has been a visiting scholar and an invited speaker at several research institutions.

Isabel Brusca is Professor in Accounting and Finance at the University of Zaragoza, Spain. Her research and professional interests are focused on public sector accounting. She has participated in numerous research projects and is the author of several books and papers in this field. 